\title{
A actualização do direito reclama conhecimentos sobre a sua utilização histórica recente Direito e direitos humanos
}

\begin{abstract}
António Pedro Dores ${ }^{1}$
Resumo: O direito, o direito democrático, tem vindo a perder influência, dignidade e prestígio, nas últimas décadas. Impressiona o descartar dos direitos humanos e da democracia, a par da impotência profissional e política para denunciar a degradação evidente do respeito dos princípios de direito distintivos da nossa civilização. A soberania popular constituinte, as relações dos direitos entre os povos, os seus representantes e a política, são sempre problemáticas. Mas há épocas, como as que vivemos, onde é preciso voltar a pensar nelas, para as actualizar. A sobrevalorização da normalidade democrática, do fim da história e das ideologias, a par da desvalorização da soberania e da política, da vontade e das opções populares, correspondem à desresponsabilização cívica da prática profissional (colaboradores em de vez de trabalhadores) e do ensino (escolarização das massas) favoráveis a vocações técnico-pragmáticas, tornando o ambiente inabitável às vocações filosófico-doutrinárias. É tempo de revisitar as origens do programa humanista de tarefas sociais e políticas a que, tacitamente, estamos vinculados, em particular o positivismo do século XIX e os direitos humanos da segunda metade do século XX, para melhor compreender como será possível contribuir para a necessária actualização do direito e, de facto, dos saberes.

Palavras Chave: direito; democracia; vocação, especialização.

Abstract: Law, the democratic law, loses influence, dignity and prestige, in the last years and decades. Human rights and democracy are set aside, as much as the professional and political abilities to denounce and fight back the clear lack of respect of the western way to produce and give life to legal principals. Constitutional popular sovereignty, rightful and legal relations between peoples, its representatives and politics are always problematic. However, there are epochs, as the one we live in, when it becomes necessary to rethink all the arrangements and update them. The emphasis to the democratic normality, to the end of the history and ideologies, contrasts with the disdain to politics, sovereignty, popular will and stated popular options. At civic and professional levels, people are devalued (they become collaborators instead of workers), as well at school level (mass school). This ambience recommends vocational and pragmatic horizons to teachers, students and workers. It becomes much difficult to develop doctrinaire or philosophical perspectives. One need to recall the $19^{\text {th }}$ and second part of $20^{\text {th }}$ century's origins of humanistic program and its social and political tasks: positivism, human rights. It would help to look the past to build innovative perspectives to law and, in general, wisdom.

Keywords: Law; democracy; vocation; specialization..
\end{abstract}

\section{Direito e direitos humanos}

Os últimos desenvolvimentos na política europeia, a respeito das finanças gregas, revelam um clima de agressividade entre os estados, apelando a sentimentos nacionalistas, marcado pelas mentiras (ao ponto de ter sido acordado um plano de resgate, o terceiro, reconhecidamente inexequível por ambas as partes) e pelas chantagens, em que cada uma das partes intenta processos de intenção à outra.

O que é que o direito tem a ver com tal situação?

Como chamou a atenção Maria Luísa Malato neste colóquio, a retórica é a arte primeva de procurar representar a verdade material (inatingível) através do seu émulo, a verosimilhança discursiva. É um dos fundamentos técnicos e políticos do direito: o

${ }^{1}$ Professor do departamento de sociologia no ISCTE-IUL, apad@iscte.pt . 
que parece é, costuma dizer-se. Quando a verosimilhança está excluída de uma base de entendimento entre as partes, pode dizer-se que falta matéria para que o direito possa fazer caminho, isto é, regular as relações sociais através da razão. Quando isso envolve decisões cruciais da União Europeia, alegadamente respeitadora da democracia, do estado de direito e dos direitos humanos, há quem justificadamente tema estar-se na presença de um sinal de fim de um tempo para os países europeus. As regras velhas não são respeitadas e as novas ainda não foram formuladas.

Primeiro declarou-se a crise financeira. Depois anunciou-se a crise social. Mais tarde tornou-se patente a crise política. A crise jurídica era-lhes anterior, pelo menos em Portugal. Vive-se actualmente, neste aspecto, um contra ataque de alguns poderes judiciais, ganhando prestígio por atingirem algumas figuras do regime, banqueiros e um ex-primeiro-ministro, com acusações criminais. Levantam-se teorias da conspiração sobre porque prende este e não aquele? "Que dê os outros?" - como dizia há uns anos o humorista Jô Soares.

A nível internacional, a existência mítica de um conselho clandestino de sábios, federador de todas as sociedades secretas, torna-se realidade prosaica quando o Eurogrupo, entidade onde se tomam decisões sobre a vida dos cidadãos e sobre as relações entre estados, se auto-declara grupo informal, sem tutela jurídica ou política formal. A soberania popular constituinte, a normatividade da regulação de direito entre os povos, os seus representantes e a política, abaladas pelos referendos repetidos até darem o resultado esperado, revelam-se ultrapassadas pela informalidade ao mais alto nível. Sem registo de manifestações de surpresa geral. Nem nos partidos do regime, nem nos outros. A independência e autonomia entre os poderes executivo e judicial estão tão fragilizadas como limitadas as possibilidades de cooperação entre órgãos de soberania

O direito, o direito democrático, tem vindo a perder influência, dignidade e prestígio, nas últimas décadas. Em Portugal, passou-se do tempo em que a maioria dos deputados eleitos era de juristas, para um sistema de contratação externa da produção legislativa a empresas de advogados eventualmente representadas por deputados na Assembleia da República mas, sobretudo, com influência junto dos poderes instalados nos aparelhos partidários e empresariais dominantes. A um excesso de advogados no mercado da política seguiu-se um recuo dos juristas principais do espaço público para as antecâmaras do poder oligárquico.

Impressiona a irresponsabilidade com que os juristas descartam os critérios doutrinários dos direitos humanos e da democracia, ou melhor, a sua impotência profissional e política para denunciar a degradação evidente do respeito dos princípios de direito distintivos da nossa civilização. De que modo a formação de juristas poderá contribuir, naquilo que lhe cabe, para reverter a actual situação, em Portugal e na Europa? É a este assunto a que dedicamos de seguida atenção.

Usaremos o positivismo e os direitos humanos como âncoras para pensar as relações entre a evolução das sociedades modernas e os usos contraditórios do direito. Com a violência, da Revolução Francesa ou da $2^{\mathrm{a}}$ Grande Guerra, surgem direitos à paz e ao respeito mútuo. Para logo emergirem os conflitos sobre o valor efectivo e a legitimidade real dos novos usos autoritários das normas bem-intencionadas. Usaremos, também, a relação entre o direito e a sociologia, ou, mais precisamente, a estranha falta de relação entre as duas disciplinas, apartadas pelo processo de híperespecialização. 


\section{Do positivismo}

O positivismo é uma doutrina inclinada a dispensar a coerção e a tortura. Suscita a possibilidade de neutralização das práticas vingativas das classes dominantes, em troca da estabilidade normativa. Imagina que o conhecimento sobre as leis das coisas, as leis naturais e as leis sociais, dispensa e não recomenda a acção autoritária, quando o objectivo é resolver problemas. Os críticos vêm nisso uma desconsideração para a política, contra a gaiola de aço burocrática de que falou Max Weber, uma esperança irrealista de os problemas humanos serem sobretudo práticos.

Os códigos jurídicos sinalizam e formalizam o que não se deve fazer e como se reagirá em caso de violação das regras. Imaginando que a lei se impõe a todos e a cada um, incluindo às classes dominantes. As penas devem respeitar a dignidade humana. O tempo de prisão é, tão só, a suspensão temporária de direitos de autodeterminação ambulatória. Tempo durante o qual os condenados têm direito de se conformar ou reagir, reclamando a verificação da qualidade do conhecimento jurídico em vigor relativamente ao respeito pela sua condição humana.

Durkheim (1960) concebe o trabalho do direito como paralelo e complementar ao da sociologia: ambos têm por finalidade descobrir e actualizar os conhecimentos sobre como funciona a sociedade, para ele equivalente de consciência social ou solidariedade, para a respeitar. O sancionamento das práticas sociais deveria ser feito conforme a consciência colectiva, determinada esta pelos estudos, jurídicos e sociais, da verosimilhança do sucesso da integração social dos indivíduos e do bem-estar geral. A retórica judicial, portanto, seria a voz pública do conhecimento disponível sobre a consciência colectiva, isto é, de como a solidariedade social está pronta a funcionar em cada momento. Os sinais jurídicos, argumentos, decisões, sansões, servem de orientação para colocar nos carris as práticas sociais consideradas indesejáveis e desadequadas.

O positivismo prevê o uso da relação biunívoca entre aquilo que se sabe e é e aquilo que se diz, entre o mundo ontológico e o mundo virtual, como modo seguro de orientação coerente e científica da acção das pessoas. Funda-se na convicção de as vidas adaptadas ao modo moderno de viver serem mais felizes do que aquelas que se debatem com a procura de formas de adaptação ou inadaptação inovadoras. Isto é, ter desejos de ser diferente, não se encaixar na divisão de trabalho habitual, gostar de viver num mundo diferente, são atitudes que não devem ser alimentadas, por não serem positivas.

A sociedade moderna, porém, ao contrário das sociedades de antigo regime, não deveria ser dura com o crime. Afinal, a destruição criativa, que Schumpeter (1961) haveria de reconhecer mais tarde, já era o motor das sociedades europeias mais avançadas no final do século XIX. Para tirar proveito da criatividade haveria de a controlar e sancionar, mas de modo humano, sem alienar a condição humana do criminoso-inovador. Embora fosse necessário conter a anomia (crime/criatividade) em níveis aceitáveis, havia que reconhecer a utilidade da inovação para benefício de todos. Durkheim recomendou a paulatina abolição das penas de prisão, substituídas por multas ou por outras alternativas a penas físicas, como maneira de afirmar a modernidade.

A esta esperança positivista corresponde, em termos liberais, a norma de utilização apenas em última instância das condenações criminais. Mais vale não condenar um arguido culpado do que fazer penar um inocente, costuma dizer-se. Os ideais positivista e liberal contrastam com a realidade actual, quando as prisões são instituições globais, presentes em todos os países, e usadas em quase todos de modo a que a sobrelotação é um dos principais problemas identificados, a par do desrespeito 
pelos direitos humanos e pela reincidência, isto é, o falhanço do tratamento punitivo e ressocializador, incapaz de servir de prevenção. Ao invés, quem passe pela prisão vê aumentada a probabilidade de voltar a ser condenado por cometer crimes.

A finalidade clássica das penas, a ressocialização, está desqualificada como teoria inconsequente. Cumprindo a teoria a função de separar o mundo entre aqueles que falam, em particular nas universidades, na administração, nos tribunais, na política, e o mundo dos que vivem as consequências do "braço secular" do direito na pele, os presos e os profissionais que lidam directamente com eles nas prisões (Dores \& Preto, 2013) e noutros territórios violentos, ideologicamente escondidos dos olhares modernos (Hirschman, 1997; Ruggiero, 2000).

Nas últimas décadas, não apenas em Portugal, mas no mundo ocidental em geral, com destaque para os EUA, a sobrelotação crónica das prisões é resultado de bagatelas penais (Wacquant, 2000) produzidas pelas políticas proibicionistas (Woodiwiss, 1988). Na Europa, continente dos direitos humanos, todos ou muitos dos sistemas penitenciários não respeitam as normas penitenciárias europeias (Crétenot, 2014). Há um direito nos livros e há o direito dos tribunais. A que se deve acrescentar a ausência de direito nas prisões. Ausência que se expande para fora das prisões. Com as políticas de medo, com a construção de condomínios fechados, com a existência de bairros populares onde a polícia não entra a não ser ao tiro, como numa guerra, com a imprensa sensacionalista (Dores, 2013), etc.

\section{Anti-positivismo}

Anos atrás, dois sociólogos portugueses acusaram-se mutuamente de serem positivistas, sendo o termo usado como expressão depreciativa. Um, mais académico, acusava o outro de holismo, de pretender explicar toda a realidade com uma fórmula geral, essencialista, mágica. Outro, mais crítico, acusava o seu oponente de empirismo, de imaginar poder dispensar incluir a reflexão política e ideológica geral na análise social. Outro autor, de cuja referência lamentavelmente não disponho, notava como o positivismo passou a estar presente na sociologia recente através do anti-positivismo, isto é, o acordo entre quase todas as correntes teóricas em renegar, uns mais por este aspecto e outros mais pelo outro, o positivismo, sem todavia conseguirem libertar-se dele. Mouzelis (1995) aponta este bloqueio dizendo que, desde Parsons, a teoria social sofre de reificação e reducionismo. Por outras palavras: inventa cenários onde possa colocar as peças soltas imaginadas como autónomas do conjunto.

Para a análise das relações entre a teoria social e o direito, é interessante fazer o contraponto entre o direito constitucional e o direito aplicado no dia-a-dia, por um lado, e a sociologia crítica, holista, face à sociologia académica, mais preocupada com a minuciosa análise de dados empíricos, por outro lado; de um lado a necessidade do trabalho com a filosofia e, do outro lado, a atenção aos protocolos técnicos habituais. Mas o mais relevante é o acordo entre praticamente todas as correntes sociológicas e do direito em omitirem a centralidade social, política e empírica da violência nas vidas das pessoas. Sobretudo, claro, as com menos recursos de auto-defesa.

Hirshman (1997) e Elias (1990) mostram diversas facetas de como a ideologia moderna tornou a violência tabu. Com a urbanização, refere Foucault (1999), a violência deixou de ser exposta e motivo de honra e passou a exercer-se burocraticamente, kafkianamente, sistematicamente, dentro de muros, como incorporação. Criou-se um mundo auto-disciplinado, automatizado, de autómatos humanos assalariados, de recursos humanos em que cada trabalhador é uma unidade de matéria-prima mais ou menos disciplinada e qualificada. Em contraponto com os 
mundos da marginalidade, das liberdades, dos negócios, do empreendedorismo ou da exclusão miséria. O mundo moderno, na produção e no consumo, é feito como um puzzle: as peças são reunidas pela imaginação publicitária que nos ocupa o espaço público, as televisões, o correio, a satisfação das necessidades essenciais, a mente e o corpo.

O pacifismo pós II Grande Guerra, consequência das experiência directa dos horrores da destruição da Europa e do plano Marshall de reconstrução, conduzido pelos EUA, reforça esta tendência de fazer tabu da violência (Malešević, 2010:1-5, 17). $O$ pacifismo positivista, reagindo às violências revolucionárias e da reacção contra revolucionária do século XIX, deu uma ênfase exagerada à ordem, ao mesmo tempo que mantinha vivas as esperanças num mundo melhor, com a ajuda da razão. Por exemplo, na esperança de um dia se perder o hábito dos castigos corporais como forma de pena judicial, por mera evolução moral natural dos sentimentos de repugnância contra a tortura, aceitou manter e reforçar o tabu cognitivo contra os estudos sobre a natureza da violência e, também, da própria natureza humana. Há, pois, um padrão epistémico que, no século XIX e na segunda metade do século XX, reage com espírito positivo à experiência do inferno belicista, imaginando um mundo novo finalmente sem conflitos, ou como se diz hoje, o fim das ideologia e o fim da história, na verdade repetindo Marx e Engels que imaginaram o comunismo como o fim da luta de classes e o fim da pré-história da humanidade.

$\mathrm{O}$ alheamento do direito e da sociologia da violência penal - e das guerras mantem-se firme. Os castigos corporais, a tortura e os genocídios não pararam de aumentar.

No plano cognitivo, o positivismo não provou a alegada capacidade humana de fazer a correspondência biunívoca entre o que se diz e o que se faz. O mundo prático, violento, é densamente povoado de segredos, mistérios e até trivialidades tão banais que ninguém se lhes refere. Como as penitenciárias. O mundo virtual, cognitivo, é construído letra a letra, máquina a máquina, imagem a imagem, por muitos computadores. Mas o objectivo disso não é reproduzir a realidade. O contrário: serve para criar um outro mundo, hipnótico e sedutor, alienado do mundo vernáculo. Para efeitos de funcionamento da economia, mas também para prazer das pessoas modernas.

O que tem acontecido é o empobrecimento da reverência tradicional camponesa perante a natureza, tratada actualmente praticamente só como escrava dos nossos desejos. Uma crise financeira é pretexto mais que suficiente para a suspensão de toda a reflexão ecológica, tornada segunda, terceira ou enésima prioridade.

O anti-positivismo apontou o irrealismo da pretensão positivista de reduzir o mundo das representações a meros significantes de significados materiais; reclamou os prazeres da subversão epistémica como postura mais digna e satisfatória de viver de acordo com a doutrina dominante; as desigualdades sociais e as lutas de classes mantiveram-se e eternizaram-se. Foi-se perdendo a esperança de um mundo novo. Abriu-se espaço ao relativismo. As universidades passaram a ser pontos de encontro de especialidades cognitivas que se desconhecem mutuamente (Lahire, 2012:319$356)$.

Voltemos ao exemplo das penitenciárias para mostrar como funciona o relativismo. O abolicionismo prisional, vigoroso e optimista dos anos setenta, imaginou que o estado realizaria a abolição pelo facto de lhe ser apresentada racionalmente a impossibilidade das prisões cumprirem as suas finalidades institucionais. A história, porém, seguiu rumo bem diferente. Transformou as penitenciárias num sector económico florescente em França, no Reino Unido, na Austrália, e sobretudo nos EUA encarregues de encarcerar 1/4 dos 10 milhões presos de 
todo o mundo (Gilmore, 2007). A obscura doutrina do nothing works (Martinson, 1974) terá informado uma cultura penitenciária (Garland, 2001) que se permite interpretar a lei contra si mesma. Na prática, o que foi abolida foi a pretensão das leis, como as das finalidades das penas, obrigarem os estados ou os funcionários. À margem da lei, políticos sem escrúpulos beneficiaram da cumplicidade da opinião pública, a chamada imprensa popular ou de escândalos, para implementar políticas conhecidas como tolerância zero e troca de segurança por liberdades, associadas a guerras lançadas a pretexto de mentiras, sem condenação judicial. Com os anos e a crise, a xenofobia e o racismo tornou-se um problema, no sistema criminal europeu (Palidda \& Garcia, 2010; Palidda, 2011) e na política.

Esta abolição tácita das normas em vigor pelas interpretações relativistas do direito, da sociedade, do estado, da violência, da legitimidade política, da finalidade das instituições, é uma das características do nosso tempo. De que as crónicas mentiras dos políticos são apenas um fenómeno mais evidente. E o aumento da procura de serviços jurídicos um sinal. A sua melhor compreensão reclama uma profunda crítica epistemológica capaz de romper com o alheamento entre as ciências positivas, naturais ou duras, e as ciências sociais, humanas ou moles (Damásio, 1994). A que as ciências jurídicas serão chamadas a dar o seu contributo.

A verdade deificada atribuída ao Livro, ou à caverna de Platão, como uma forma de continuar o estado mental imaginado pelos nominalistas para o estado teológico, foi alvo de uma elaboração célebre, por Augusto Comte. Após a superação dos estados mais primitivos de consciência humana, defendeu o autor da Lei dos Três Estados, o estado positivo de consciência permitiria ter certezas científicas. O retorno à pureza original, in principio erat Verbum, et Verbum erat apud Deum, num estado superior de evolução, era uma aspiração pós-revolucionária muito apreciada. Karl Marx também imaginou o comunismo como uma forma mais elevada do comunismo primitivo. O pensamento positivo prometia ser capaz, ao mesmo tempo, de oferecer textos premonitórios e realistas, como as instruções de montagem dos produtos de bricolage.

Cinco séculos após a invenção da imprensa, os ecrãs e a internet criam virtualmente mundos inimagináveis. A imposição da universalidade da cultura, do pensamento e dos conflitos ocidentais, que de alguma forma esteve na base do sucesso do positivismo, contestada internamente - por ser incapaz de oferecer o que prometia, uma imagem fidedigna da realidade, a biunivocidade entre textos e palavras, leis e sentenças - e externamente - por ser colonialista, opressora e destruidora - continua a funcionar mas agora de outro modo: através do panóptico materialismo consumista associado ao uso hipnotizante da imaginação, como num casino ou num centro comercial (Bauman, 2000).

É provável que as novas maneiras de imaginar a vida, a vida em sociedade, a moral, o direito, a sabedoria, venham a ter efeitos práticos, ou já estejam a tê-los. Mas não serão, nunca foram, como desejaram os positivistas: não basta enunciar a lei natural ou humana para que ela produza realidade. O que não significa que diferentes enunciações sejam indiferentes à realidade: a realidade é cada vez mais feita de enunciações. Mas, por outro lado, nenhum mundo virtual, por muito rico que seja, será capaz de tornar-se independente do mundo material, do destino cósmico do planeta, cuja trajectória pode ser influenciada mas não negada pela espécie humana.

Os relativistas dominantes, os neoliberais, mostraram que não é preciso mudar as instituições para as subverter (Jakobs \& Meliá, 2003). Aproveitando a incapacidade actual de construir uma alternativa real à epistemologia positivista e negando-a nos seus aspectos a reter: a saber, a vantagem de intercomunicação entre saberes, como o 
direito e a sociologia, e a necessária atenção à violência para a regular, em termos nacionais, internacionais e ecológicos.

\section{Dos direitos humanos}

A liberdade aristocrática (Boétie, 1997), capaz de comparar uma pessoa com Deus, repudia o mecanicismo ou o organicismo associados ao positivismo. As relações biunívocas entre os materiais, as práticas e as equações matemáticas são tecnologicamente úteis e provaram a sua eficácia. Nos campos social e jurídico (ou diplomático), porém, fora da natureza, não há relações biunívocas eficientes. Há autodeterminação (Foucault, 2004).

(Augusto Comte, além de positivista, era um excêntrico fundador de uma religião própria; Newton era também um alquimista. O Deus de Newton era o Cosmos. O de Comte era a sociedade; a sociologia seria a ciência síntese de todas a ciências. Esta religiosidade científica rompia com a distinção cartesiana entre o sagrado e o profano, o espírito e o corpo, separação que ainda hoje conforma todo o nosso pensamento subordinado às duas culturas (Snow, 1956). O positivismo, na prática, foi usado pela contestação racionalista e realista aos segredos e às incoerências românticas do século XIX, conforme nos dá conta Eça de Queiroz, em Os Maias, na cena do debate literário no jantar de amigos. Com o desgaste das lutas, perdeu o fulgor e, também, a capacidade de impor um pensamento pós-cartesiano, de que tando necessitamos hoje em dia para compensar os excessos de especialização e isolamento cognitivos).

O uso de qualquer tecnologia, como o fogo ou as pontas de sílex, reclama a presença do direito, para que os conflitos supervenientes possam ser enfrentados (Supiot, 2002): quem (não) guarda? Quem (não) usa? Quem (não) toma posse? Quem (não) controla? O direito é uma forma de sabedoria de ponta, na medida em que é confrontado com as inovações. Através dos conflitos emergentes das novidades, cujos apaziguamentos e normalização lhe são requisitados, os juristas afeiçoam as sociedades e as pessoas ao seu devir. As penas são formas de impor soluções e de condicionar futuros conflitos através da regulamentação. Construída uma tradição, ela deve ser imposta, a menos de alegações capazes de se lhe encontrar defeito (como na lógica positiva) ou do uso da força para redesenhar desejos, aspirações e direito. $\mathrm{O}$ direito, como pensava Marx, será uma superestrutura. Embora não apenas uma decorrência do modo de produção, do taylorismo, do fordismo, da gestão line, consoante o modelo de gestão de recursos em moda. Terá o seu papel na produção de legitimidade política e social dos poderes do dia.

Para além da função positiva do direito, aplicada sobretudo nos regulamentos e na burocracia, há uma função nobre do direito: a função constituinte. A representação do soberano ausente, o povo.

As sociedades, e os tribunais, são mais ou menos conservadores conforme são mais ou menos permeáveis ao debate sobre as regras jurídicas previamente estabelecidas e às interpretações correntes sobre como devem ser aplicadas. Após a Revolução Francesa, como também após a Revolução dos Cravos em Portugal, os julgamentos expeditos e emocionais reclamaram dos juristas uma inclinação conservadora. Para que o direito pudesse ser ponderado. Positivismo significa fixar alguma segurança através da estabilidade das normas e das interpretações legítimas. Como se as sociedades, os factos, as pessoas fossem coisas. Impõe um respeito pelo normativo alheado das causas sociais dos litígios, sempre complexas, variáveis, difusas e susceptíveis às emoções. Procede-se a uma naturalização do direito, como se fosse intemporal e rotineiro. 
No tempo actual de aceleração das mudanças sociais e tecnológicas jamais experimentado e face a ondas sucessivas de nova legislação, os juristas são estimulados a dispensar reflexões elaboradas, a dar prioridade à sua própria precária empregabilidade, a adiar (definitivamente?) preocupações próprias de mentes cultivadas, que demoram décadas a produzir quando se é competente e se está suficientemente bem apoiado profissionalmente. A produção em massa de juristas teve o efeito de trazer à profissão pessoas dispostas a cumprir os mínimos para funcionarem e sobreviver. A proletarização dos juristas organizada pelo estado e pelas sociedades de advogados, as novas práticas disciplinares e de avaliação das profissões jurídicas, a sindicalização de magistrados, são sinais que explicam a consensualidade corporativa defensiva, longe dos ideais liberais de serviço à sociedade. $\mathrm{O}$ positivismo no direito refere-se, hoje, a um trabalho avesso ao confronto filosófico e sociológico com a vida que pode ser pensada fora da retórica casuística e dos quadros habituais das práticas judiciais consagradas burocraticamente.

A situação actual é instável e em mudança de direcção imprevisível. A actual despolitização e os novos modos de funcionamento em rede, utilizando a internet (Castells, 2004, 2012), remetem-nos para um novo mundo capaz de auto-gestão, caso aprenda a usar a informação disponível a todo o tempo para tratar de qualquer problema. Pequenos grupos de afinidades, uns locais outros globais, podem partilhar entre si soluções para problemas particulares através do mútuo conhecimento ao mesmo tempo muito especializado, humano, pessoal e tecnologicamente distanciado. Um discurso único totalitário, incompatível com a vertigem do mundo actual mas bem acolhido por quem requer segurança (como aqueles viajantes agarrados aos ferros na montanha russa) aumenta a alienação entre o que se faz e aquilo que se diz. O aumento das guerras (50 vezes (Morris, 2013:621)) e dos genocídios (Malešević, 2010:269; Santos, 2014) é apresentado como um mundo de paz.

A sociedade do risco (Beck, 1992) não se refere a um mundo higienizado, urbanizado, armado até aos dentes. Refere-se à consciência difusa da insustentabilidade prática do mundo actual e dos projectos das classes dominantes, nomeadamente o extrativismo, tanto social como ambiental (Acemoglu \& Robinson, 2013; Acosta, 2013; Francisco, 2015). A organização da produção, portanto o taylorismo, o fordismo, a burocracia, a tecnologia, etc., não pode continuar ser pensada apenas como problema prático, ao cuidado de engenheiros. E o direito aplicável teria vantagem em ser pensado em função dos efeitos práticos nos trabalhadores (Quiñonero, 2010), nos consumidores e na humanidade. Sabe-se hoje que a economia e o progresso não resolvem todos os problemas. Pior, constituem-se em graves problemas para a humanidade e o ambiente. É tempo de inverter a separação que Adam Smith promoveu entre a moral e a economia. A ética é, também, um problema prático quando está em causa o aquecimento global. Supiot tem razão: cabe ao direito ponderar os modos de utilização legítimos das tecnologias. Nas guerras, na produção industrial e nas relações laborais.

Do mesmo modo que Descartes separou analiticamente as partes do todo, Adam Smith a moral da economia, o positivismo separou o direito de códigos sem ideologia da sociedade esquiva e imperfeita das desigualdades sociais.

A separação entre sociologia e direito positivos, evidenciada pela existência de várias faculdades de direito e sociologia, em vários países europeus, cujos departamentos separados não conseguem organizar actividades conjuntas, é um caso particular da separação em partes estanques da realidade complexa, para fins de estudo especializado. A necessidade de mútua penetração foi reconhecida pelos arquitectos da justaposição dos departamentos de sociologia e direito. Algo estrutural, porém, impede a realização dessa colaboração. Será possível ultrapassá-lo? 
O mesmo fenómeno que separa cognitiva e praticamente as partes mecânicas de um motor - ou do universo newtoniano - separa também o direito da sociedade, o direito nos livros do direito nos tribunais, o direito da sociologia, os princípios do direito e a sua aplicação prática.

Quadro 1. Diferenças e semelhanças entre Direito e Penitenciárias

\begin{tabular}{|c|c|c|}
\hline \multicolumn{2}{|c|}{ Diferenças } & \multirow[t]{2}{*}{ Semelhanças } \\
\hline Direito & Penitenciárias & \\
\hline Sucesso multissecular & Fracasso secular & Ideal igualitário \\
\hline Adequa princípios a situações & Adapta pessoas a situações & Justiça casuística \\
\hline Diz-se & Faz-se & Sistema de recursos \\
\hline Regula sociedade & Exclui da sociedade & Identificam anormalidades \\
\hline $\begin{array}{l}\text { Solidariedade na partilha de } \\
\text { soberania }\end{array}$ & Socialmente selectivas & Segredos de Estado \\
\hline
\end{tabular}

Os direitos humanos, fonte de legitimidade da construção da humanidade solidária, espécie de um povo só, sofrem do mesmo problema: de que servem as declarações, quando na prática não são tidas em conta (Crétenot, 2014)? Os diálogos entre a moral e a técnica, entre a filosofia e as profissões, entre o poder judicial e a sociedade, entre os valores universais e a diversidade da vida, podem ser desbloqueados? A favor da humanização da humanidade? A favor da liberdade e da igualdade?

\section{Para o ensino do direito}

A relação do direito moderno com o povo é problemática. Apesar das constituições típicas da modernidade se distinguirem por consagrarem o povo como o soberano, a traição do soberano parece ser um dos desportos favoritos dos grupos dominantes.

$\mathrm{Na}$ teoria, podemos associar a genuinidade popular a movimentos constituintes e a entropia politiqueira à normalidade institucional. Mais tarde ou mais cedo, o envelhecimento dos mecanismos constitucionais abre portas a toda a espécie de distorções e perversões. Os reformistas pensam poder resolver o problema lubrificando os mecanismos testados pelo tempo, aprimorados pela crítica. Os revolucionários pensam ser necessário começar de novo, mudar de ambiente, fazer falar o povo, que já mostrou - embora em ocasiões excepcionais - ter o poder de purificar as esperanças num futuro entusiasmante. Mas a que custo?

$\mathrm{Na}$ Grécia, povo e direitos humanos estão na ordem do dia. O governo que marcou o fim do regime bipartidário do PASOK-Nova Democracia denunciou a crise humanitária vivida no país; diagnóstico que foi aceite sem discussão pelos dignatários europeus. Com o referendo sobre as negociações da dívida grega ficou a saber-se a disposição popular de assumir a sua vontade autónoma relativamente ao status quo.

Mais uma vez, de forma dramática, o soberano representado sob a forma eleitoral foi traído pelos políticos. Temendo-se a possibilidade de expressão da vontade popular por meios violentos (Mitralias, 2015). Qual é o lugar do direito, neste período histórico? Será verbo-de-encher, superestrutura que se moldará aos poderes fácticos, como pensava Karl Marx? Poderá tornar-se uma arma do soberano para defesa dos seus direitos constitucionais, como defendem Eric Thoussant e outros 
(AAVV, 2015), a nível internacional, denunciando a dívida como um velho processo de exploração sem mérito?

Em termos práticos, poderão os estados estabelecer com instituições financeiras contratos ruinosos para si próprios em nome do resgate do sistema financeiro global, demasiado grande para falir, como tem denunciado Paulo Morais (Lopes \& Brígida, 2014) em Portugal? Ou, ao invés, os estados devem fidelidade política e jurídica ao soberano, o povo, a quem devem assegurar os direitos constitucionais, políticos, económicos, sociais e culturais? As empresas e sobretudo as grandes empresas serão elementos privilegiados do povo, como acontece nos EUA onde estão reconhecidos os direitos de cidadania das empresas? Poderão tratados internacionais determinar, por contrato, a submissão das finanças de estados soberanos à competência de tribunais sujeitos a formas de soberania não popular, como o tratado orçamental na UE ou como o TTIP pretende generalizar? Ou, em sentido inverso, haverá interesse e possibilidade de estender a eficácia do direito à defesa da natureza, como reclamam Bolívia e Equador nas suas constituições, sem saberem como o fazer na prática?

Que povo poderá impor uma ordem jurídica à actual oligarquia globalmente dominante? Que direito terá esse povo?

Foi Max Weber quem distinguiu, precisamente, os juristas formais, agarrados às leis como se elas fossem boias de salvação para não se confrontarem com a vida social e para se conformarem com a autoridade da melhor interpretação, e os juristas abertos ao mundo, atentos às práticas, usando o direito para promover e desenvolver o seu próprio sentido de justiça, em diálogo com a sociedade, as instituições e os outros interessados. À vocação técnica, limitada à eficiência descritiva dos casos, opõe-se a vocação doutrinária e filosófica, centrada no debate sobre a legitimidade das interpretações dos princípios aplicáveis.

Quadro 2. Regimes de orientação profissional de juristas

\begin{tabular}{|l|c|c|}
\hline & Economicismo & Humanismo \\
\hline Formalismo & Abstenção política & Abstenção ideológica \\
\hline Intervencionismo & Construção de mercados & Direitos humanos \\
\hline
\end{tabular}

A Enciclopédia foi uma descrição das capacidades e potencialidades criativas dos ofícios, de como a acção formava a moral, o trabalho se orientava por requisitos sociais. Herdeiros do Iluminismo, mas também das resistências aristocráticas ao trabalho, nunca deixámos de separar, com a clareza possível, o trabalho manual e o trabalho criativo, a rotina imposta e a liberdade individual, a submissão e a marginalidade.

Com o desenvolvimento do capitalismo tardio, a exploração da força de trabalho submetida estende-se às profissões liberais, sujeitando-as a profundos processos de proletarização. Retirando o chão à criatividade intervencionista própria das liberdades aristocráticas liberais. Ou melhor, monopolizando essa potencialidade profissional no topo das sociedades: nas direcções das empresas de advocacia, e até nos tribunais (Sousa, 2015), alheadas e protegidas do direito. Tais práticas remetem a democracia para o palco das impotências indecentes. Transportando o debate jurídico do plano cívico para o plano conspirativo, reflectido na disputa político judicial em torno de redes de corrupção que se apontam mutuamente em público. 
A impunidade nos negócios públicos, de que as Parcerias Público Privadas e os seus ex-ministros actuais gestores das concessões são o símbolo, contrasta com a desprotecção no acesso ao direito dos cidadãos, dos arguidos e dos condenados. Qual é a responsabilidade, se ela existe, dos juristas nesta situação?

Alguém um dia atribuiu a Dostoievki a ideia de "uma visita às prisões mostrar o grau de civilização de um povo". O respeito pelos direitos humanos, ou mais precisamente o desrespeito, mostra, certamente, o grau de predominância dos juristas formalistas sobre os intervencionistas, dos juristas situacionistas sobre os constituintes. Como refere Paulo Morais (Lopes \& Brígida, 2014), quando os próprios deputados são reféns dos partidos e dos interesses privados que colonizam a Assembleia da República, o formalismo torna-se o nó górdio. E coloca a questão de saber se o ensino do direito está adaptado aos tempos que correm. Havendo inquietações sobre as melhores formas de elaborar uma formação adequada às necessidades: qual o lugar do povo na ordem jurídica actual e futura? Soberano ou à distância? Qual o lugar da sociologia (nas suas vertentes de análise tecnológica e moral, por exemplo) nos cursos de direito?

\section{Fecho}

Infelizmente, a necessidade, todavia evidente, de mudança criativa na formação de juristas não está na ordem do dia; em contraste com os fortes ventos de mudança, em sociedade. Queira-se ou não, resista-se ou não, as transformações sociais, para o melhor ou para o pior, afiguram-se profundas, no próximo futuro. Deverá o ensino do direito preparar o choque da sociedade com o futuro? Poderá e saberá fazê-lo?

A crise financeira grega e europeia, as lutas contra a corrupção, as vocações dos juristas, as prisões, a filosofia das ciências, os direitos naturais, o povo, o direito. O que se pode recomendar é a substituição de uma lógica centrípeta, caracterizada por uma hiperespecialização disciplinar (Lahire, 2012:319-356) por uma orientação centrífuga, não apenas nas ciências naturais e sociais (Damásio, 1994; Prigogine, 1996) mas também no direito.

No século XIX, num momento pós-revolucionário, o positivismo fixou a nova doutrina da liberdade, igualdade e fraternidade. Foi usado como uma arma de luta contra os segredos sociais, como o incesto aristocrático denunciado em Os Maias, ou o escamoteamento das vidas duras dos trabalhadores, denunciado pelo neo-realismo, ou os privilégios, de que os debates jurídicos haveriam de passar a presumir a bondade da sua abolição. O anti-positivismo reagiu ao sucesso intelectual dessa corrente, apontando-lhe as limitações. A especialização cartesiana, utilizada para a afirmação do positivismo, dividiu à nascença sociologia e direito positivos. Tornou-se empirismo nas ciências sociais, e formalismo em direito: tornou-se simplista, rígida e dogmática. Não constituindo obstáculo à desqualificação das práticas profissionais entretanto proletarizadas. A desqualificação do direito e do poder das organizações judiciais públicas, a favor da privatização dos serviços jurídicos, segue o seu curso contra natura.

No meio da agudização das lutas de classes, na segunda metade do século XIX, o positivismo era revolucionário. Com o tempo, ficou conhecido como uma ideologia conformista de defesa da ordem estabelecida. Nem filosofia, nem religião, nem ideologia, o positivismo reclamava um sincretismo pacificador, avesso ao cartesianismo. Mas esgotou-se nele.

Estamos, porém, numa época de revisitar as origens e os seus fundamentos. Nomeadamente o falhanço escandaloso das promessas inacabadas de igualdade e 
fraternidade, como complementos das liberdades. A derrota do sonho holista de uma sociedade nova e um homem novo, lembram-se? Ficou o pesadelo cartesiano da hiperespecialização.

Tocqueville, na senda de Descartes, separou a subtileza aristocrática do sentido de liberdade (por exemplo, participando na gestão da coisa pública para proveito próprio) e a evidência popularucha de como agir pela igualdade (nomeadamente, imitando os comportamentos aristocráticos quotidianos e anulando as leis que legitimaram os privilégios). Desdenhou da democracia, a tradução política do igualitarismo, alegando os riscos das paixões populares acabarem necessariamente em despotismo. Tocqueville, como Adam Smith e muitos outros, separou a ética da moral e esta da economia, como quem separa princípios e fins, equiparando os primeiros à nobreza e os segundos ao trabalho operativo. (Esta epistemologia marcou as ciências sociais até hoje: Mouzelis (1995) refere-se a isso como reificação (dos princípios) e reducionismo (do alcance do trabalho). Regista a inibição da capacidade cognitiva associada a esses defeitos). A teoria, separada da prática, replicou e reproduziu o espírito separado da matéria, o superior separado do inferior. A humanidade separada do mundo, que nos permite, ainda hoje, pensar o nosso progresso contra a natureza e o ambiente, explorando ambos como escravos. E explorando escravos e grande arte dos assalariados como se fossem naturezas mortas.

As mesmas dinâmicas centrípetas e de especialização alegadamente pragmática (há quem diga burocrática (Bernardo, 1997; Graeber, 2015)) foram mobilizadas através das concepções de separação de poderes de Montesquieu e do método analítico de Descartes, até à hiperespecialização actual. Opuseram-se a elas, de certa forma, positivistas como Durkheim.

Em Formas Elementares da Vida Religiosa, o autor refere a separação radical entre o mundo profano, a que poderíamos chamar também quotidiano ou prático, e o mundo sagrado, o mundo virtual ou susceptível à manipulação, criado em momentos de excitação em que sonhamos acordados. A separação do mundo em quotidiano de trabalho rotineiro e festividades de intensa e renovadora sociabilidade, porém, é da ordem das representações. O mundo real é o mesmo, alterado pelos estados de espírito criados pelas diferentes situações. Os estados de espírito exaltados, a que o observador pode ser imune no seu esforça de neutralidade (por exemplo, quando se dá conta da diferença dos nomes profano e sagrado atribuídos, pelas mesmas pessoa, à mesma colina ou à mesma árvore), não devem ser ignorados porque são fenómenos sociais. A desmultiplicação de linguagens consoante o âmbito social das relações a estabelecer provam a existência real de diferentes estados de espírito. Falar de sociologia em português, para a comunidade dos seus falantes, revela-se também em estados de espírito bem diferentes dos captados e captáveis pela sociologia em inglês, como bem sabem os avaliadores internacionais (Bennett, 2011).

A natureza humana, é isso que se pode concluir, é ao mesmo tempo una (religada pelo carácter multipolar das práticas humanas) e irremediavelmente desconexa, entre o que se faz e o que se diz. Esta exposição da natureza humana como unidade e diversidade mutuamente relacionadas é homóloga da do cristianismo: Deus Pai (os princípios inscritos eternamente nas palavras e hábitos herdados, como um espaço), Deus Filho, como Homem (as práticas escolhidas em cada momento por cada um, no tempo) e o Espírito Santo (a fecundidade e o mistério da vida na Terra). Profundamente marcada ideológica e civilizacionalmente.

A sociologia e o direito, apartados como estão entre si, são produto e sintoma da estratégia cognitiva centrípeta-cartesiana. A sua confluência, a realizar um dia, será produto de uma outra estratégia cognitiva, centrifuga. No dia em que os tribunais poderem acolher formas de avaliação dos contextos macrossociais, como sugeriu John 
Rawls (1993), muita coisa terá mudado. Talvez nessa altura a sociologia tenha aprendido a identificar os estados de espírito que transformam a mesma realidade em outra coisa, por força da mente humana.

\section{Referências bibliográficas}

AAVV., Truth Commission on the Greek Debt, 2015. Acesso em 22 de Julho de 2015 http://greekdebttruthcommission.org/wp/?tag=eric-toussaint

ACEMOGlu, D., \& ROBInSON, J. A., Porque Falham as Nações - as origens do poder, da prosperidade e da pobreza. Lisboa: Círculo de Leitores, 2013.

ACOSTA, A., El Buén Vivir - Sumak Kawsay, una oportunidad para imaginar otros mundos. Barcelona: Icaria\&Antrazyt, 2013.

BAUMAN, Z., Liquid Modernity. Cambridge: Polity Press, 2000.

BECK, U., Risk Society: Towards a New Modernity. London: Sage, 1992.

BENNETT, K., Academic Writings in Portugal. Coimbra: Imprensa da Universidade de Coimbra, 2011. Acesso em 18 de Setembro de 2015 a https://digitalis.uc.pt/en/livro/academic_writing_portugal_i_discourses_conflict

BERNARDO, J., Marx contra Marx, 3 vol. Porto: Afrontamento, 1997.

BOÉTIE, L., Discurso Sobre a Servidão Voluntária. (Antígona, Ed.) (1 a ed. 154.). Lisboa, 1997.

CASTELLS, M., A Galáxia Internet - Reflexões sobre a Internet, Negócios e Sociedade. Lisboa: Fundação Caloust Gulbenkian, 2004.

CASTELLS, M., Redes de Indignación y Esperanza. Madrid: Alianza, 2012.

CRÉTENOT, M., Das Práticas Nacionais Para as Recomendações Europeias: iniciativas interessantes de Gestão das Prisões. Lisboa: Antigone Edizioni Observatório Europeu das Prisões, 2014. 
DAMÁSIO, A., O erro de Descartes: emoção, razão e cérebro humano. Lisboa: Europa-América, 1994.

DORES, A. P., A análise jornalística torna irreconhecível a densidade da vida. Revista Angolana de Sociologia, (11), 35-50, 2013. Acesso em 18 de Setemrbo de 2015 a http://hdl.handle.net/10071/6782; http://ras.revues.org/320

DORES, A. P., \& Preto, J., Segredos das Prisões. Cascais: RCP edições, 2013.

DURKHEIM, É., De la division de travail social. Paris: PUF, 1960.

ELIAS, N., O Processo Civilizacional (Vol I e II). Lisboa: D. Quixote, 1990.

FOUCAULT, M., Microfísica do Poder. Rio de Janeiro: Graal, 1999.

FOUCAUlT, M., A Hermenêutica do Sujeito. São Paulo: Martins Fontes, 2004.

Francisco, P. CARTA ENCÍCLICA LAUDATO SI' (2015). Santa Sé. Acesso em 19 de Setembro de 2015 http://w2.vatican.va/content/francesco/ pt/encyclicals/documents/papa-francesco_20150524_enciclica-laudato-si.html

Garland, D. (2001). The Culture of Control - Crime and Social Order in Contemporary Society. Oxford: Oxford University Press.

Gilmore, R. W. (2007). Golden Gulag - prisons, surplus, crisis and opposition in globalizing California. Berkeley: University of California Press.

Graeber, D. (2015). The Utopia of Rules - On Technology, Stupidity, and the Secrets Joys of Bureacracy. London: Melville House Publishing.

Hirschman, A. O. (1997). As Paixões e os Interesses. Lisboa: Bizâncio.

Jakobs, G., \& Meliá, M. C. (2003). Derecho Penal del Enemigo. Madrid: Cuadernos Civitas.

Lahire, B. (2012). Monde pluriel. Penser l'unité des sciences sociales (Couleur de.). Paris: Seuil. 
Lopes, A. S., \& Brígida, A. (2014, 29 de Novembro). Paulo Morais: "Sócrates é um dos principais actores na triste peça da corrupção em Portugal.” I, pp. 21-23. Lisboa.

Malešević, S. (2010). The Sociology of War and Violence. Cambridge: Cambridge University Press.

Martinson, R. (1974). What works? Questions and answers about prison reform. The Public Interest, (35), 22-54.

Mitralias, Y. (2015). Grécia: uma capitulação portadora de ameaças mortíferas. Acesso em 6 de Setembro de 2015 a http://www.tlaxcalaint.org/article.asp?reference $=15836$

Morris, I. (2013). O Domínio do Ocidente (1ª ed. 201.). Lisboa: Bertrand.

Mouzelis, N. (1995). Sociological Theory: What Went Wrong? - diagnosis and remedies. London: Routledge.

Palidda, S. (2011). Racial Criminalization of Migrants in the 21st Century. (S. Palidda, Ed.). London: Ashgate.

Palidda, S., \& Garcia, J. Á. B. (2010). Criminalización racista de los migrantes en Europa. (S. Palidda \& J. Á. B. Garcia, Eds.). Granada: Comares Editorial.

Prigogine, I. (1996). O Fim das Certezas. Lisboa: Gradiva.

Quiñonero, J. P. (2010, September 10). Nueva ola de suicidios en France Telecom. ABC.es. Madrid. Acesso em 15 de Setemrbo de 2015 a http://www.abc.es/ 20100910/internacional/suicidios-france-telecom-201009101823.html

Rawls, J. (1993). Uma Teoria de Justiça. Lisboa: Editorial Presença.

Ruggiero, V. (2000). Crime and Markets - essays in Anti-Criminology. Oxford: Oxford University Press.

Santos, B. S. (2014). Epistemologies of the South - Justice against Epistemicide. Paradigm Publishers. 
Schumpeter, J. (1961). Capitalismo, Socialismo e Democracia. (G. Allen \& U. Ltd., Eds.) (Editora Fu.). Rio de Janeiro: OrdemLivre.org.

Snow, C. P. (1956). Duas Culturas. Lisboa: D.Quixote.

Sousa, F. A. de. (2015, 10 de Septembro). ONU critica: juízes em Portugal são preconceituosos. Diário de Notícias. Lisboa. Acesso em 10 de Septembro de 2015 a http://www.dn.pt/inicio/portugal/interior.aspx?content_id=4769822

Supiot, A. (2002). Travail, droit et technique. Droit Social, 13-25.

Wacquant, L. (2000). As Prisões da Miséria. Oeiras: Celta.

Woodiwiss, M. (1988). Crime, Crusades and Corruption - Prohibitions in the United States, 1900-1987. London: Piter Publisher.

Recebido para publicação em 05-09-15; aceito em 02-10-15 